$\mathrm{Oz}$

$1-1-2005$

\title{
Hangil Book Hall and Camera Obscura
}

Follow this and additional works at: https://newprairiepress.org/oz

Part of the Architecture Commons

(c) $(1) \Theta(\Theta$

This work is licensed under a Creative Commons Attribution-Noncommercial-No Derivative Works 4.0 License.

\section{Recommended Citation}

(2005) "Hangil Book Hall and Camera Obscura," Oz: Vol. 27. https://doi.org/10.4148/2378-5853.1420

This Article is brought to you for free and open access by New Prairie Press. It has been accepted for inclusion in Oz by an authorized administrator of New Prairie Press. For more information, please contact cads@k-state.edu. 


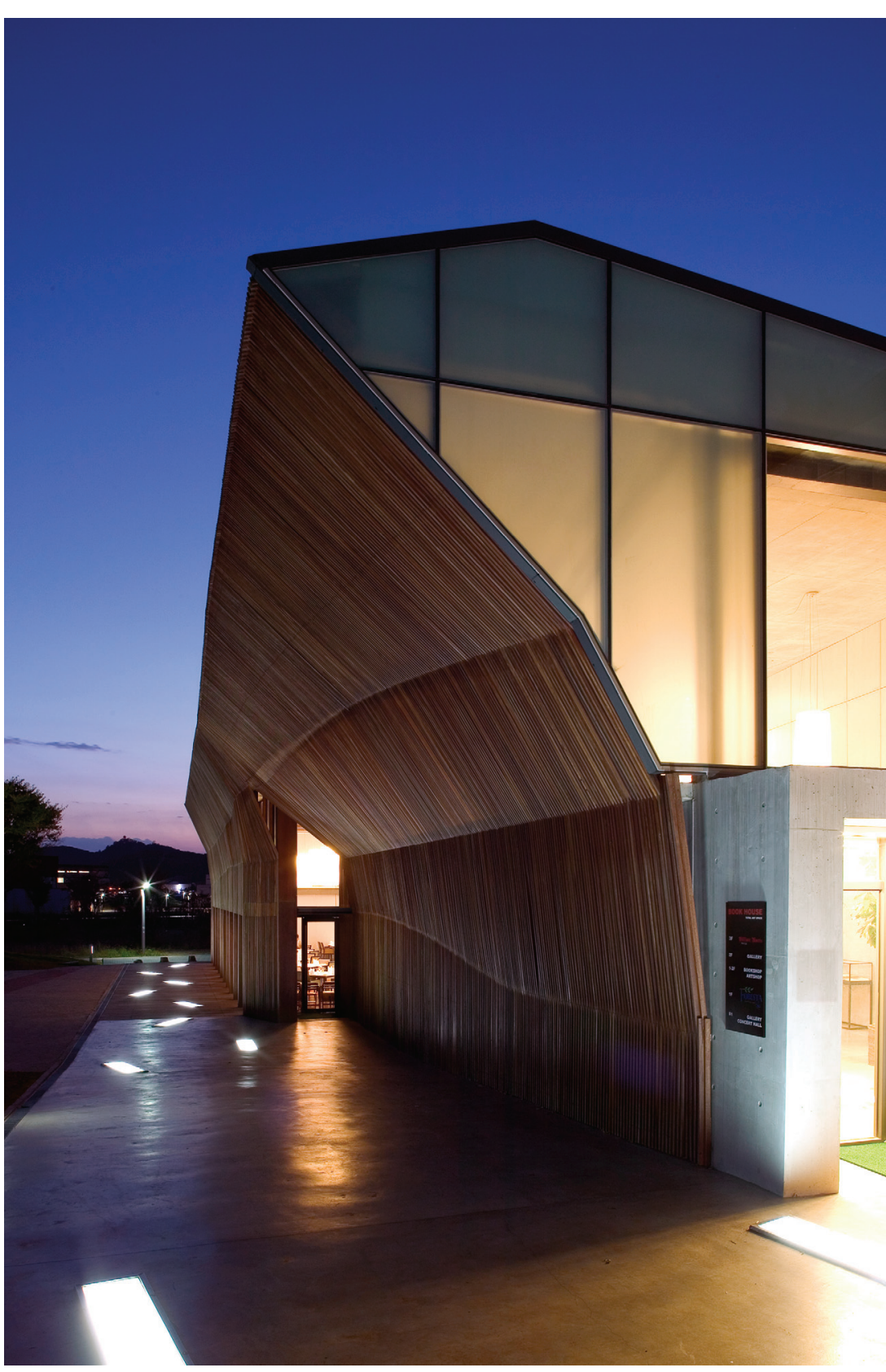

\section{Hangil Book Hall}

In fall of 2001, SHoP Architects received the commission for a building for the Heyri Art Valley master plan currently being executed one hour north of Seoul, South Korea in the city of Paju in the Province of Kyong-gi Do. The project is being planned by M.A.R.U. (Metropolitan Architecture Research Unit), a local firm, on land comprised of six hills and valleys with a change in elevation of 94 meters. Operating at multiple scales, the village will become a 24-hour community committed to the production and exhibition of art related activities. Studio residences, exhibition and concert halls, commercial film studios and museums are planned.

Located at the base of one of the six hills defining the Art Park, the Hangil Book Hall for Hangil Publishing, a premiere publisher of art and philosophy books in Korea, was conceived as a built landscape. The Art Park of Heyri is interlaced with roads and paths winding and connecting the disparate parts of the complex into a natural whole. The path becomes an important extension of the landscape and blends the experience of the architecture to its natural surrounding. The Book House is divided into two distinct zones: a vertical bar enclosing a three story book wall with ramps connecting to the outdoor reading space on the hillside and a large hall housing mixed use programs from a restaurant to performance and exhibition space open to a large plaza.
The Book House is linked to the surrounding hillside by a wood-planked pathway that extends into the building and wraps the three-story book wal forming the spine of the book bar. The path forms a continuous line of movement bridging the wooded landscape of the hillside to the interior spaces of the Book House, modeling a fluid passage of space and movement and merging a variety of different programs into a seamless sequence of experiences and unfolding views of the surrounding landscape. Anchoring each landing of the ramp is a different reading space. Upon climbing the first ramp one enters into the children's reading room with a view to a shallow pool enclosed by a concrete retaining wall. Through the pixilated wall of book shelves, light streams in from a clerestory window running the length of the book wall, offering views of the steep and densely wooded hillside. A thickend scrim composed of multiple layers of baleen like strips of dark stained "ipe" wood forms a continuous concave wood surface that folds over the exhibition hall to form an undulating wood surface on the roof of the building. Within this dynamic density of wood, a landscape of benches and inclined surfaces for reclining have been incorporated to heighten the seamless relationship between the built and the natural. It is this warping wood fabric culminating at the roof that embodies a sense of connection of the Book House to its natural surroundings and offers a panoramic view of Heyri. 


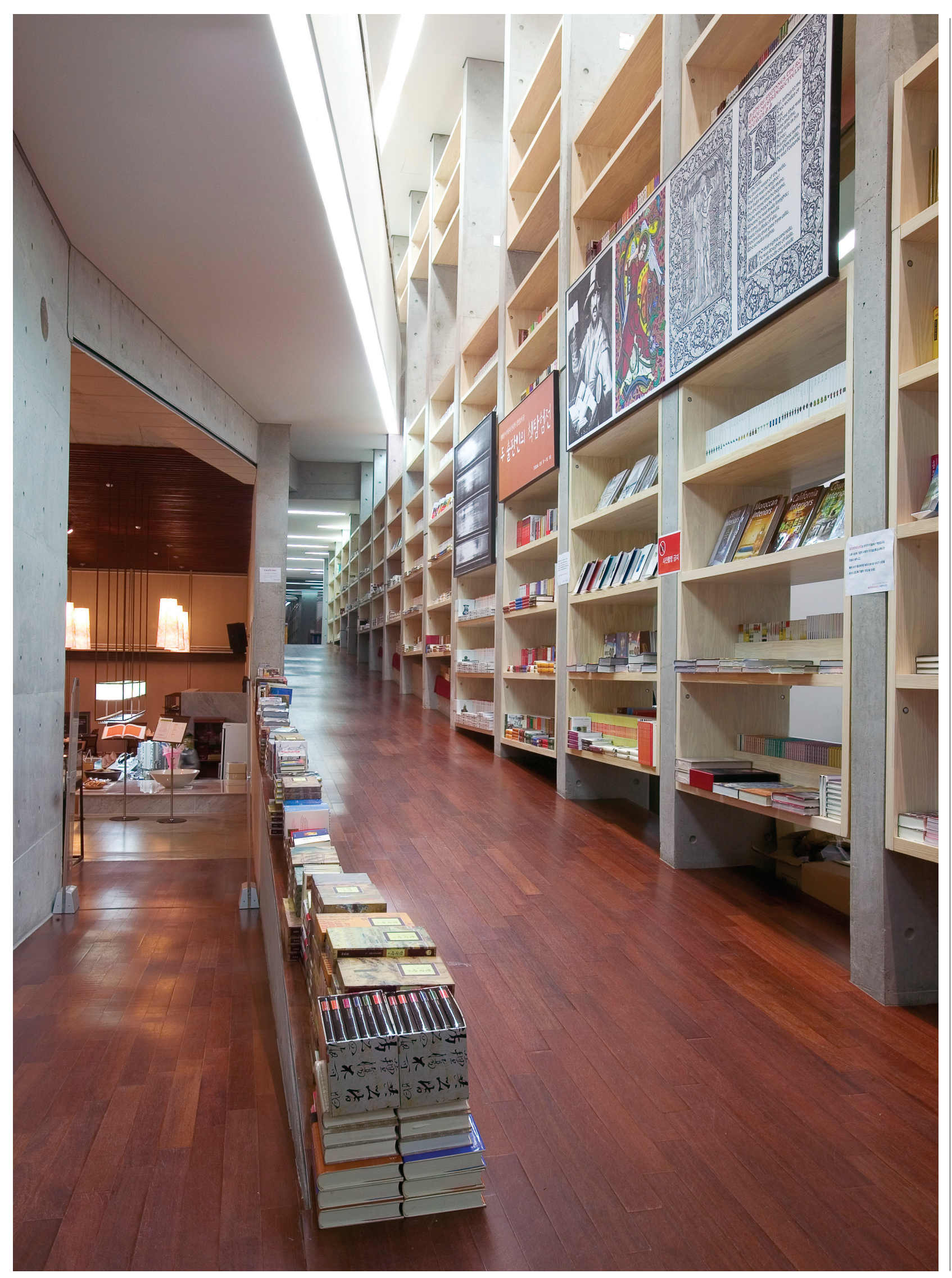



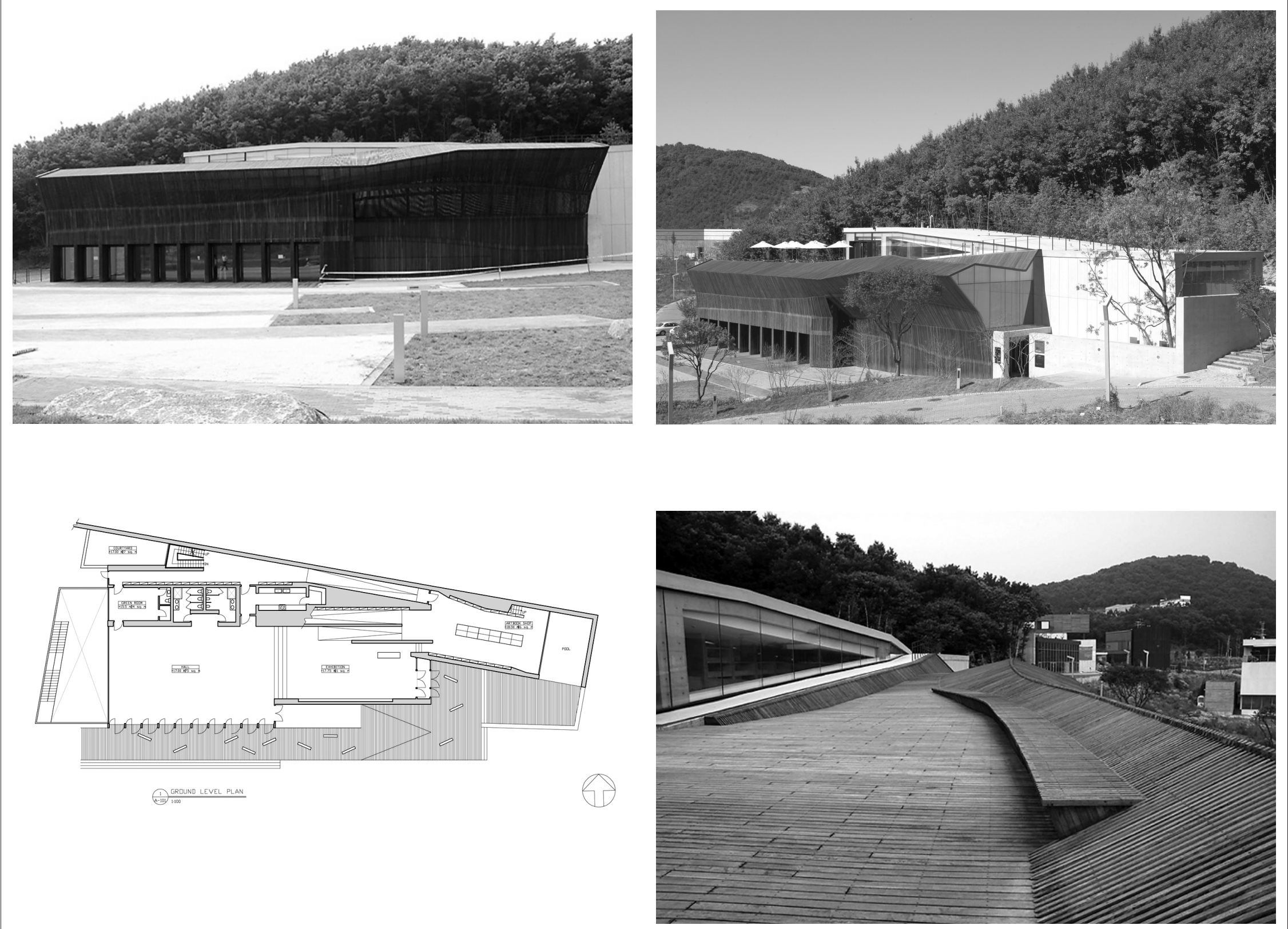


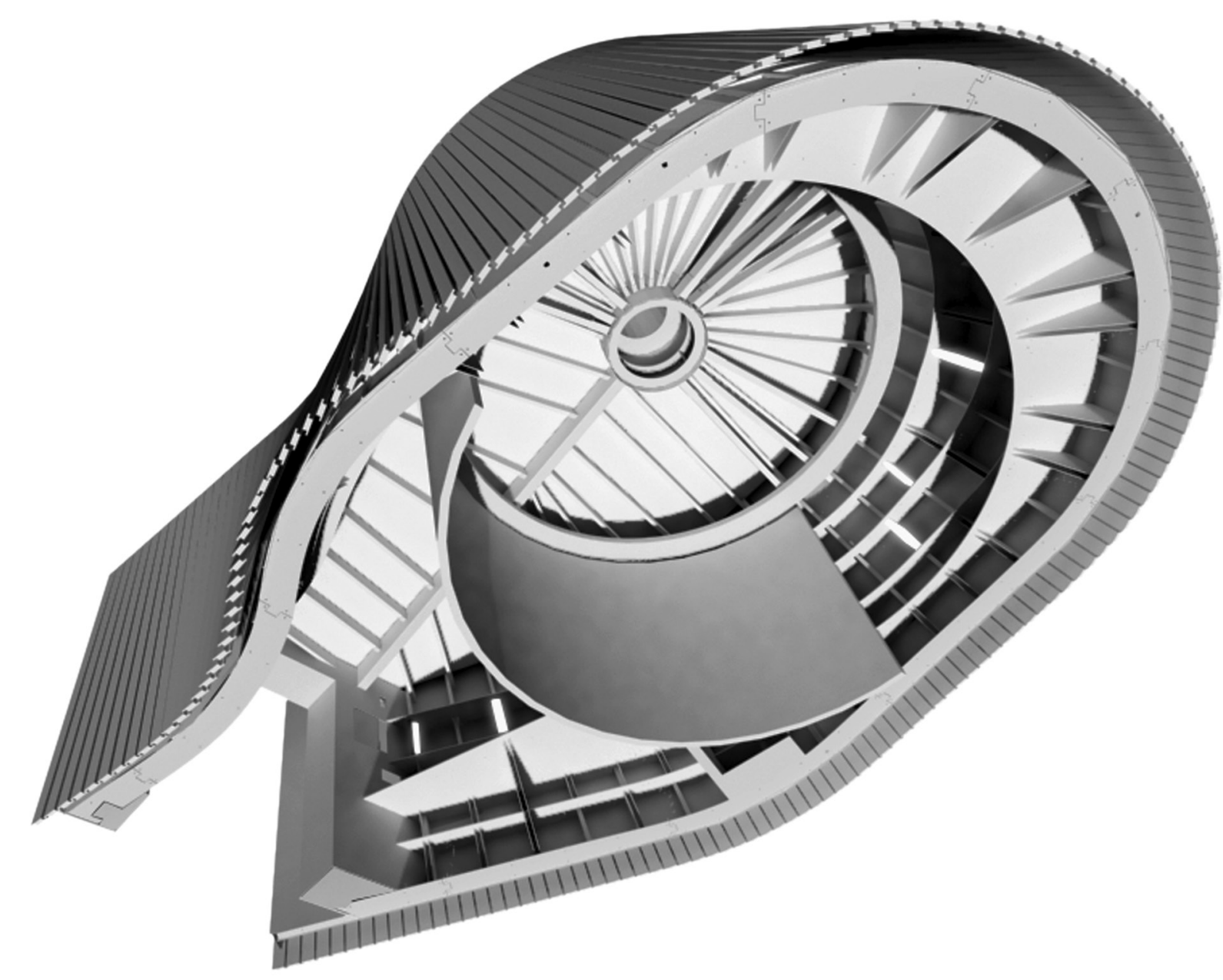

\section{Camera Obscura}

An apparatus that has fascinated people since the fourteenth century, the Camera Obscura (Latin for dark room) is a novelty in today's world. Through an optical lens and a mirror, a live image of the Camera's surroundings is projected down onto a flat, circular table that is raised or lowered to adjust focal depth. As such, the building is conceived of and operates as a camera. This notion manifests itself through the Camera's architecture, from its movable components and material properties, to its sublime form and strategic situation in Mitchell Park East. The Camera's lens can focus on all buildings and elements in Mitchell Park (carousel house, amphitheater, ice rink, mister-plaza, ferry terminal building, etc.) or out to the marina and beyond to Shelter Island, across the bay. Further, given the scale and scope of the building, this project was driven by a "Research and Development" attitude, in an attempt to tie the nostalgic program of the Camera Obscura with today's cutting edge technology in terms of both design and construction process.

Designed entirely as a 3-D computer model, the construction of the Camera is communicated as a kit of custom parts accompanied by a set of instructions much like those that one finds with a model airplane kit. Primary aluminum and steel components will be laser-cut using digital files directly extracted from the computer model, with crucial information etched into the components for ease of fabrication Full-scale templates will be provided for wall and roof sheathing, a black paper-resin board called SkatelitePro produced for use primarily in skateboard/BMX freestyle parks, noted for its ability to accept a high degree of curvature. Much of the fabrication will take place off-site; pre-fabricated panels will bolt into the concrete foundation and to each other, ensuring the required level of precision for the rest of the Camera's structure and elements to bolt and screw onto. The subtly warped exterior skin is comprised of milled "ipe" hardwood planks, the same wood that is deployed throughout all of Mitchell Park.

\section{Project Facts and Credits}

Location of Project:

Village of Greenport, Greenport, NY

Client/Owner/Developer:

Village of Greenport

Total Square Footage:

$350 \mathrm{SF}$

Project Cost:

$\$ 170,000$

Project Manager:

Mark Ours

Project Team:

Mark Ours, Reese Campbell,Jason Anderson,

Keith Kaseman, and Basil Lee 

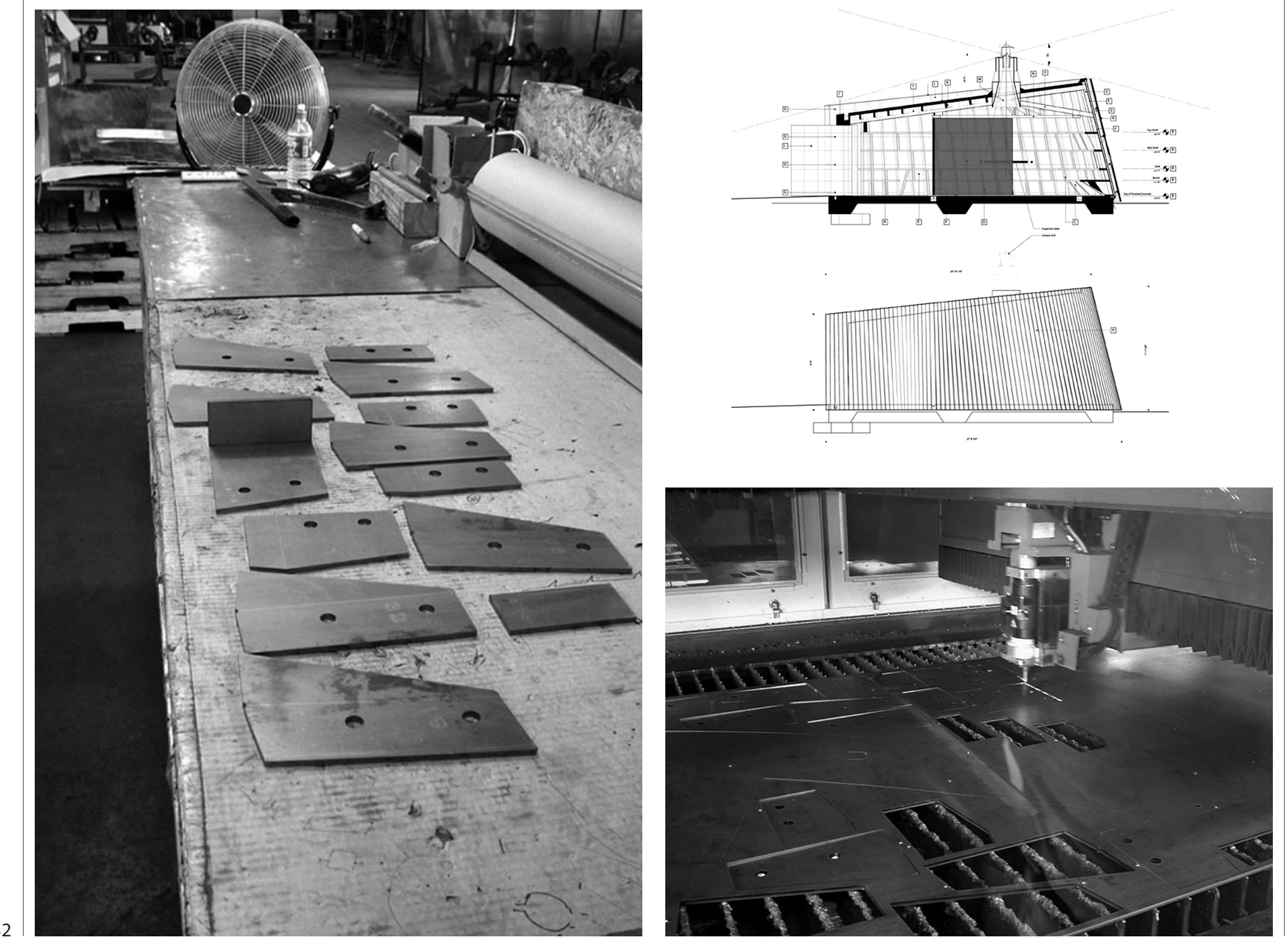

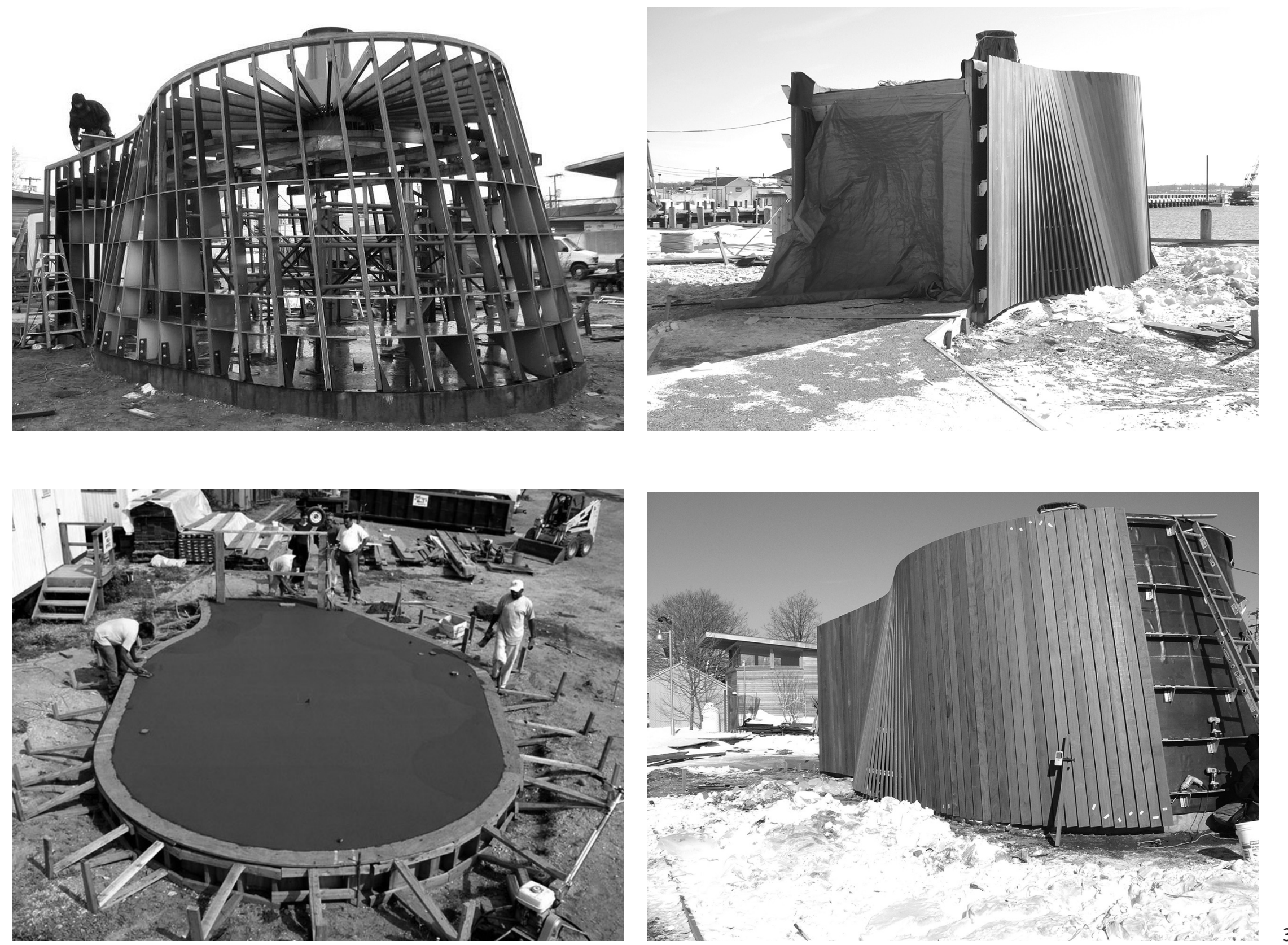